\title{
Analysis of the Mechanism of Foreign Trade Affecting Energy Consumption: Based on Chinese City Data
}

\author{
Chaohua Ma \\ College of Economics, Jinan University, Guangzhou, China \\ Email: 15625129602@163.com
}

How to cite this paper: Ma, C.H. (2020) Analysis of the Mechanism of Foreign Trade Affecting Energy Consumption: Based on Chinese City Data. Journal of Service Science and Management, 13, 118-133. https://doi.org/10.4236/jssm.2020.131008

Received: December 30, 2019

Accepted: February 11, 2020

Published: February 14, 2020

Copyright ( 2020 by author(s) and Scientific Research Publishing Inc. This work is licensed under the Creative Commons Attribution International License (CC BY 4.0).

http://creativecommons.org/licenses/by/4.0/

\section{(c) (i) Open Access}

\begin{abstract}
The vigorous development of China's economy and the rapid growth of foreign trade are inseparable from the huge energy consumption. In this paper, the decomposition analysis method is used to decompose the energy consumption growth of 285 prefecture-level and above cities in China from 2004 to 2013 into the scale, composition and technique effects. Based on the decomposition results, the IV method is used to solve the endogenous problem in the impact mechanism of China's foreign trade on energy consumption growth. It is concluded that there was a significant positive correlation between foreign trade and total energy consumption growth, mainly through positive correlation of the scale effect and negative correlation of the technique effect, and the scale effect plays a leading role, the composition effect is not significant.
\end{abstract}

\section{Keywords}

Energy Consumption, Decomposition, Foreign Trade

\section{Introduction}

Since the reform and opening-up policy was released, the degree of trade opening has been continuously improved and China's economy has made great progress. According to China Statistical Yearbook-2018, China's GDP maintained a sustained and rapid development from 1979 to 2017, with an average annual growth rate of $9.5 \%$ and an average growth rate of $18.6 \%$ in total value of import and export, especially since China's entry into the World Trade Organization, the ratio of total value of imports and exports to GDP has increased to more than $50 \%$. Foreign trade has a noticeable pulling effect on China's eco- 
nomic development.

However, the fast-growing Chinese economy and foreign trade are inseparable from huge energy consumption. According to the data of BP world energy statistics yearbook 2018, China accounted for $23.2 \%$ of global energy consumption and $33.6 \%$ of global energy consumption growth in 2017. China is still the largest energy consumer in the world. According to China Statistical Yearbook-2018, the national energy consumption in 2004 was 2.303 billion tons of standard coal, of which coal accounted for $70.2 \%$ of the total energy consumption; in 2013, the total energy consumption reached 4.169 billion tons of standard coal, of which coal accounted for $67.4 \%$ of it. China Energy Statistics Yearbook 2014 shows that during 2004-2013, the growth rate of national energy consumption shows a downward trend in fluctuations. Although China's energy structure has improved significantly, energy efficiency has improved, and energy consumption growth has slowed down during the 11th Five Year Plan period, the energy consumption pattern is still dominated by coal and oil, and the total energy consumption remains high and the number is amazing. With the continuous expansion of economic scale and the decrease of total energy reserves, energy problem has become one of the "bottlenecks" affecting the sustainable development of China's economy. In the face of the energy crisis and the strategic task of energy conservation and emission reduction, combined with the current status of China's active trade policy, an in-depth analysis of the impact mechanism of foreign trade on China's energy consumption growth has important reference and guidance significance for the formulation and implementation of energy conservation and emission reduction policies, as well as has important practical significance for promoting the sound and rapid development of China's economy.

Therefore, this paper examines China's energy consumption growth from the perspective of foreign trade. In particular, this paper decomposes the increase of energy consumption into scale, composition and technique effects, which can well study the change characteristics of energy consumption growth, and explore the mechanism of foreign trade affecting energy consumption on this basis. At present, most researchers use the national-level time series data or inter-provincial panel data to study the relationship between foreign trade and energy consumption. Considering that the prefecture-level city data as a basic analysis unit can better reflect the heterogeneity of various regions in terms of energy consumption and foreign trade openness, and can also avoid the smaller impact of the provincial panel data sample, this paper selects 285 cities at prefecture level and above in China during the years 2004-2013. Besides, we creatively take the three decomposition effects as dependent variables to build a model, which more directly reflects the impact of foreign trade on energy consumption. To more accurately estimate the impact mechanism of trade openness on energy consumption, this paper uses the IV method to effectively solve the endogenous problem in the model.

The rest of the paper is arranged as follows: the second part is the literature 
review; the third part introduces the decomposition method of energy consumption growth and explains the data source; the fourth part is the mechanism analysis of foreign trade affecting energy consumption; finally, the conclusion and policy implications.

\section{Literature Review}

The relationship between energy consumption and foreign trade has been studied for a long time at home and abroad. The research mainly focuses on the causal relationship between energy consumption and foreign trade. Research results vary due to differences in research objects and methods. Based on data of 15 Asian countries covering the period of 1980-2011, Nasreen and Anwer [1] researched the relationship between trade openness and energy consumption, and the panel Granger causality analysis shows the bidirectional causality between trade openness and energy consumption. The results are the same as those of Kyophilavong's study on Thailan [2]. While Nnaji et al. [3] concluded that there is a unidirectional causality running from energy consumption to exports using the data of Nigerian from 1970 to 2009. Erkan et al. [4] came to the same conclusion in a sample of Turkey in the period of 1970-2006. Katircioglu [5] found that there are also long and short-term unidirectional causality running from energy growth to import growth in Singapore. But Sadorsky [6] collected data of 8 Middle Eastern countries covering the period 1980 to 2007, and it reveals Granger causality from exports to energy consumption as well as a bidirectional feedback relationship between imports and energy consumption in short-run dynamics. However, Ghani [7] used data of developing countries to study the relationship between trade liberalization and energy demand and found that trade liberalization per se does not affect the growth of energy consumption, but after a certain level of capital per labor, trade liberalization is significant in reducing the growth of energy consumption. In particular, Shahbaz et al. [8] found the U-shaped relationship between trade openness in middle- and low-income countries but the inverted U-shaped in high-income countries according to the data of 91 countries during the period of 1980-2010. Besides, there are many studies on the relationship between foreign trade and energy consumption in different countries, such as UAE [9], China [10], South American countries [11] [12], Thailand [13] and so on.

The decomposition analysis method is an analysis framework for studying the characteristics of changes in things and their mechanism of action. Grossman and Krueger [14] pioneered the idea that the impact of trade liberalization on the environment can be decomposed into the scale, composition and technique effects, which is considered a bottom-up decomposition method. Cole and Elliott [15] applied this model to the energy field. Since then, many other researchers have extended the field of application of this model by bringing methodological and conceptual modifications. Tsurumi and Managi [16] decomposed the determinants of environmental quality into those three effects, and 
results showed that the technique effect was sufficient to reduce $\mathrm{SO}_{2}$ dioxide emissions, but its effect on reducing $\mathrm{CO}_{2}$ emissions and energy use is not enough, except for the case of $\mathrm{CO}_{2}$ emissions in high-income countries. Grether et al. [17] decomposed world manufacturing $\mathrm{SO}_{2}$ emissions in a sample of 62 countries that account for $76 \%$ of world-wide emissions covering the period 1990-2000, and they found that the scale and technique effects always work in opposite directions and the composition effect is uncertain. Based on the two data sources of international trade and industry pollution emissions in China, Yuan X [18] conducted a decomposition analysis of changes in China's manufacturing pollution emissions to study the impact of international trade on China's environment. The results showed that technique and composition effects have played a significant role in slowing the growth rate of manufacturing pollutant emissions, and have also rejected the assumption that China is a "pollution haven". Shapiro and Walker [19] studied the decline of air pollution in the USA between 1990 and 2008 by using this bottom-up decomposition method as well. Following this decomposition method, this paper researches the change in energy consumption of China.

\section{Decomposition of Energy Consumption Growth of China}

\subsection{Decomposition Framework}

Reference to the decomposition framework discussed in Shapiro and Walker, this paper extends this method to the field of energy consumption and decompose energy consumption growth into scale, composition and technique effects. Let $k_{j i t}$ represent the output of industry $i$ in city $j$ in year $t$, with GDP as the indicator, $y_{j i t}$ be the energy consumption per unit output, $e_{j i t}$ be the energy intensity $\left(e_{j i t}=y_{j i t} / k_{j i t}\right)$. Then the total energy consumption for city $j$ in year $t$ is

$$
Y_{j t}=\sum_{i} k_{j i t} \cdot e_{j i t}
$$

Let $K_{j t}$ represent the total GDP for all industries in city $j$ in year $t$, and $\theta_{j i t}$ be the share of the output of industry $i$ in city $j$ in year $t\left(\theta_{j i t}=k_{j i t} / K_{j t}\right)$, then Equation (1) can be expressed as follows:

$$
Y_{j t}=K_{j t} \cdot \sum_{i} \theta_{j i t} \cdot e_{j i t}
$$

Through the overall differentiation of Equation (2), the total increase of energy consumption can be decomposed into (3)

$$
\Delta Y_{j t}=\Delta K_{j t} \cdot \sum_{i} \theta_{j i t} \cdot e_{j i t}+K_{j, t-1} \cdot \sum_{i} \Delta \theta_{j i t} \cdot e_{j i t}+K_{j, t-1} \cdot \sum_{i} \Delta \theta_{j i, t-1} \cdot \Delta e_{j i t}
$$

On the right side of Equation (3), the first term represents the scale effect, which measures the change in energy consumption caused by changes in output, keeping all industrial composition and energy intensity constant. The second term is the composition effect, explaining the energy consumption affected by changes in the industrial composition, keeping the scale and energy intensity 
constant. The third term is the technique effect, which measures the effect of changes in energy intensity, keeping the other two variables constant.

\subsection{Data}

The increase in the number of prefecture-level cities and above in China has decreased since 2004. Based on the availability of data and the need for empirical research, this paper selects a relatively stable period from 2004 to 2013. By the end of 2013, there were 290 prefecture-level cities and above in China except Hong Kong, Macao and Taiwan ${ }^{1}$. The sample mainly includes 285 prefecture-level cities and above (excluding Sansha, Tongren, Bijie, Haidong and Lhasa) to avoid excessive missing values. The data mainly come from statistical data such as China Energy Statistical Yearbook, China Regional Economic Statistical Yearbook, China City Statistical Yearbook, and China Statistical Yearbook.

Because the existing statistics do not have direct data on the GDP of the sub-sector at the city level, to better reflect the changes in the industrial structure in each city, we use the proportion of the sub-sector employment-population at the city level to replace. In order to correspond to the energy consumption data of the six basic departments at the provincial level, we have classified the employed population of 19 industries in the city accordingly. Energy intensity is equal to the ratio of energy consumption to the economic output of industry $i$ in city $j$ in year $t$. However, since we can only obtain energy consumption data at the provincial level, and there is a lot of lack of value in city-level data, we use indirect calculations to obtain the energy intensity at the city level. Specifically, the provincial energy intensity is calculated according to the provincial energy consumption and GDP data. Then take the provincial capital of each province as the benchmark and the employment ratio of each industry to calculate the weighted average weight of each city so as to calculate the energy intensity of each city by industry. The provincial energy consumption data comes from the China Energy Statistical Yearbook for the corresponding year, which provides six relatively summarized basic sectors: 1) Agriculture, Forestry, Animal Husbandry, Fishery; 2) Industry; 3) Construction; 4) Transport, Storage and Post; 5) Wholesale, Retail Trade and Hotel, Restaurants; 6) Others. Energy sources include coal, crude oil, gasoline, diesel, natural gas, and electricity. In this analysis, we only consider energy consumption for end-use.

\subsection{Analysis of Decomposition Results}

Energy intensity is an important indicator to measure the quality of economic development. The differences in cities indicate the efficiency of energy production and consumption in each city, as well as the possibility of restricting economic development. Based on the calculation of energy consumption related data above, we plotted the average energy intensity of 285 prefecture-level cities and above in China from 2014 to 2013, as shown in Figure 1, indicating that

${ }^{1}$ Administrative divisions of cities can be found in China Urban Statistical Yearbook. 


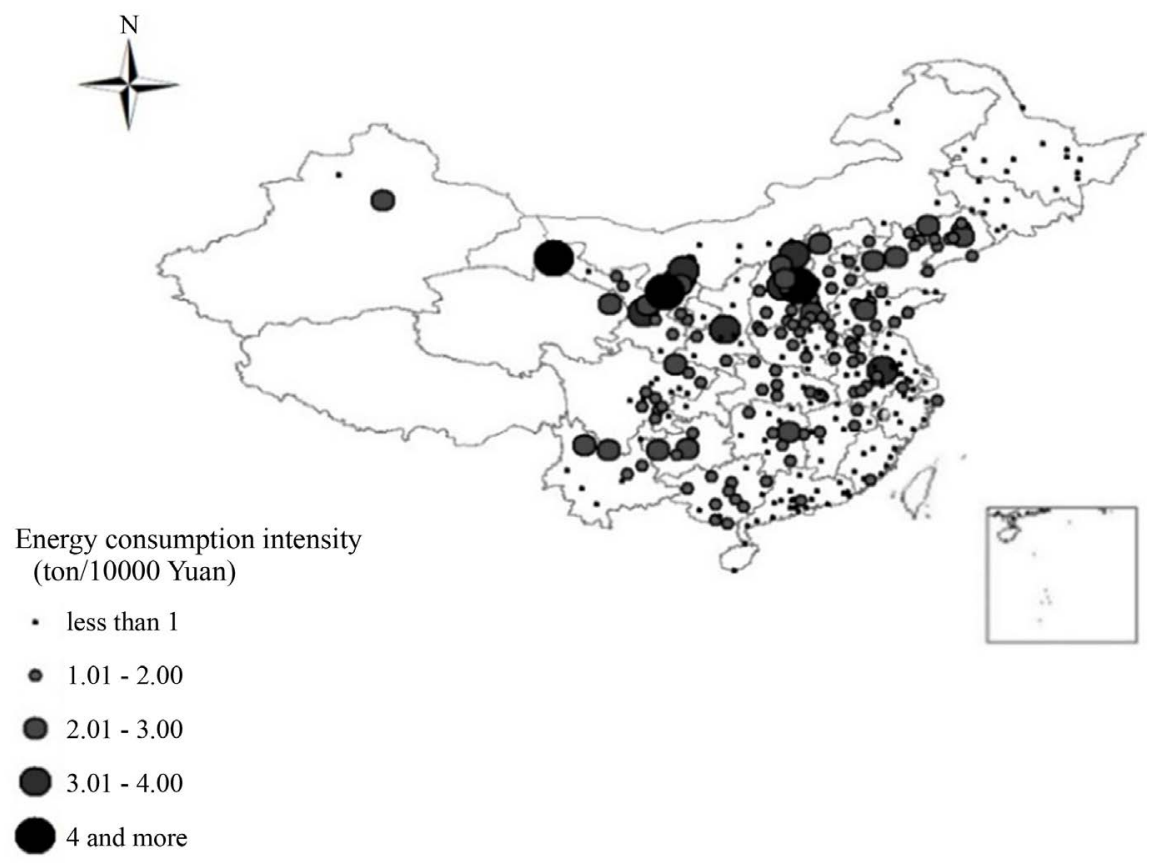

Figure 1. Average energy intensity during 2004 and 2013 (ton/Ten thousand yuan).

there were significant spatial varies in the energy intensity during this period. According to statistics, there are 148 cities with energy intensity below 1, accounting for more than half of the samples, and the location distribution is relatively scattered. Cities with the energy intensity of over 3 are concentrated in the northwest, such as Jiayuguan, Yangquan, and Zhongwei, and the energy intensity is significantly higher than the national level, indicating that they are facing great pressure to reduce energy intensity.

In order to better show the regional differences of the three decomposition effects of 285 cities at the prefecture-level and above in China, we divide these cities into four regions according to the China Regional Economic Yearbook: eastern, central, western and northeast cities, the average value of each decomposition effect of each regional city is plotted, as shown in Figure 2. It can be seen that the three decomposition effects have both consistency and significant difference in the region. The average increase in energy consumption in eastern cities is significantly larger than in other regions, which reach twice the average of northeast cities. For the three decomposition effects, the scale effect plays a leading role in all region of cities and promote a significant increase in energy consumption. The composition and technique effects work in the opposite of the scale effect, which inhibits the increase of energy consumption. In particular, the technique effect is more prominent than the composition effect, indicating that all cities have improved production technology. Combining the three decomposition effects, the inhibition of the technique and composition effects cannot completely offset the scale effect, which reflects the regional consistency. However, the contribution of three decomposition effects on energy consumption in each region is quite different. For the technique effect, the inhibition effect of the 


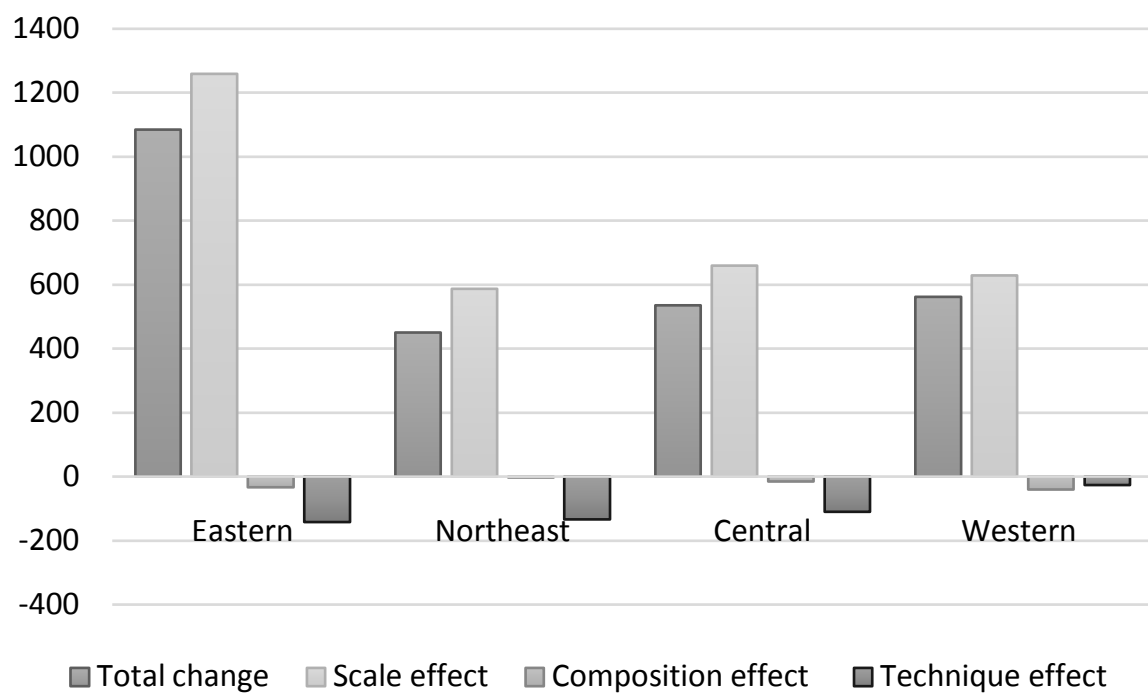

Figure 2. Average decomposition effect of cities by region during 2004 and 2013 (Unit: 10,000 tons).

northeast and central cities is obvious, with the absolute value accounts for more than $10 \%$. While in the western cities, it just accounts for about $4 \%$. The main reason for our analysis is that the implementation of energy conservation and emission reduction policies in recent years has led to a reduction in energy intensity. However, due to the smaller marginal demand for energy in eastern cities and the larger marginal demand in northeastern and central cities, the city energy intensity in the latter two regions has declined more significantly, showing a more significant technique effect. While due to economic development and technological reasons, the western cities have not shown significant technique effects. In addition, the composition effect is more pronounced in western cities and has little effect on northeast cities. It is not difficult to see that as the heavy industry base of China and it is imperative to continue to optimize the composition of industrial and energy use.

In addition, the 285 prefecture-level cities and above are divided into five levels according to the permanent population in each city in 2013: super, big, medium, small and medium, and small cities. Each level contains 57 cities. Figure 3 shows the average of three effects of cities for each level. It can be seen that the scale effect of all cities increases energy consumption, while the technique and composition effects are shown as negative effects on energy consumption, but both effects are offset by the positive scale effect, which is consistent with the results in Figure 3. Among them, the scale effect is obviously different among other levels of cities. The average value of super cities is almost three times that of other cities, and the average value of other levels of cities has little difference. The technique effect of medium-sized cities and small and medium-sized cities contribute a lot to the reduction of energy consumption, with the absolute value accounting for more than $15 \%$, while that of other cities is less than $10 \%$. The contribution of the composition effect is small, and its absolute value of each 


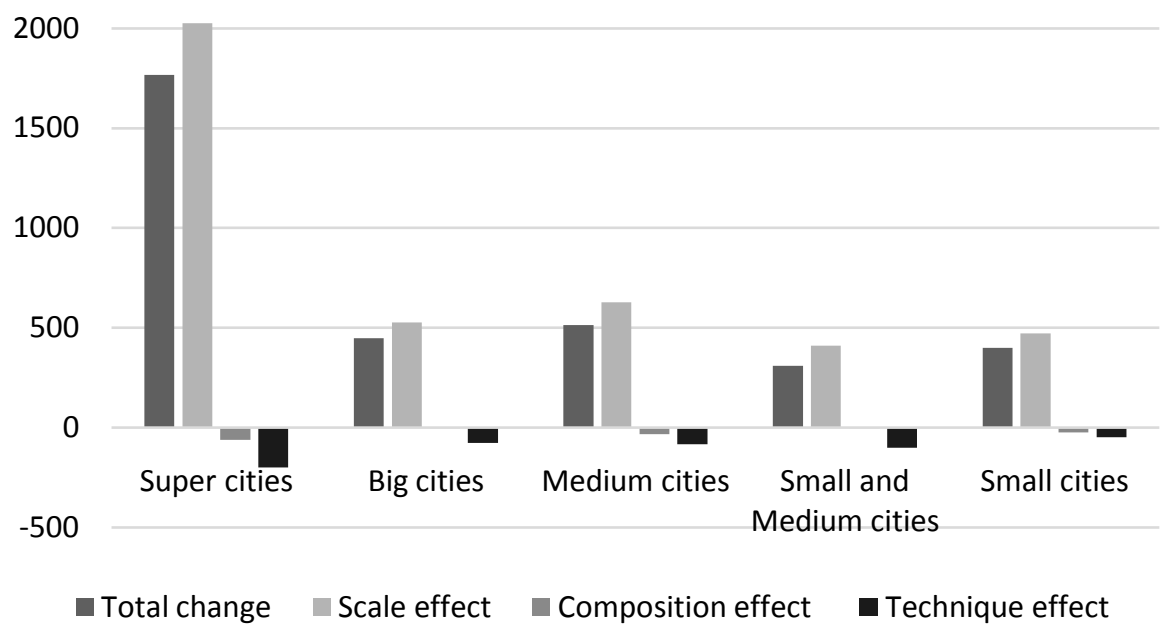

Figure 3. Average decomposition effect of cities by the population during 2004 and 2013 (Unit: 10,000 tons).

level of cities does not exceed 5\%, indicating that the positive effect of China's industrial composition adjustment on energy consumption has not really been exerted in this period. The above analysis also shows that population size is an important factor affecting energy consumption, and megacities with high population densities consume more energy.

\section{Analysis of the Mechanism of Foreign Trade Affecting Energy Consumption Growth}

This paper aims to study the mechanism of foreign trade affecting energy consumption growth. Based on the decomposition results, we can research the impacts of trade openness on these three decomposition effects so as to better understand the heterogeneity of three effects among cities. The regression model is set as follows:

$$
\Delta Y_{j}=\alpha_{0}+\alpha_{1} \Delta \operatorname{trade}_{j}+X_{j} \cdot \beta+\mu_{j}+\varepsilon_{j}
$$

\subsection{Variable Description}

Based on the decomposition results of the third part, the regression model was constructed using the total energy consumption growth from 2004 to 2013, and three decomposed effects in city $j$ as the four versions of the dependent variables $\Delta Y_{j}$. This paper uses the degree of trade openness as an indicator of China's degree of opening up, that is, the proportion of the total value of imports and exports to GDP of each city. Taking into account the spillover effect and the degree of trade openness involved in production will have an impact on the stock of economic development, we choose the average of the two years of trade openness for regression so that not only the impact of incrementality is considered, also includes the impact of stock, that is $\Delta$ trade $_{j}$. The data of the value of im- 
port and export of each city in 2013 comes from the China Regional Economic Statistical Yearbook, and the 2004 data comes from the statistical yearbooks of the provinces. The raw data of the value of import and export data in some statistical yearbooks are in US dollars. This paper uses the annual average exchange rate to convert them into RMB, and the annual exchange rate data comes from the China Statistical Yearbook.

In addition to foreign trade, factors affecting energy consumption include economic development, government environmental regulations, industrial composition and so on, so we add these factors to the model as control variables $X_{j}$. The main control variables are as follows.

The changes in GDP: In order to reduce the interference of heteroscedasticity and other factors in the model and obtain more robust results, we calculate GDP in logarithmic form and introduce the difference between 2004 and 2013 into the regression model.

Environmental regulation: The electric power industry is a basic sector in the national economy, and the current power generation method in China mainly uses fossil fuel such as oil, coal and natural gas to generate electricity and its energy consumption is huge. There are two types of electricity prices in most areas of China: regulated electricity price and government guided electricity price. The government controls electricity prices more directly, which can reflect the government's efforts in environmental regulation. Based on the above facts, electricity price is selected as the index of government environmental regulation. Due to the lack of electricity prices at the city level, this paper uses the average annual electricity price in the province where the city is located instead which comes from the China City Statistical Yearbook.

Share of the output of the secondary industry in GDP and share of the output of the tertiary industry in GDP: According to China Energy Statistics Yearbook, China's industrial energy consumption has declined since 1995, while the proportion of energy consumption in transportation, storage, postal industry, and other industries has increased slightly, implying that the industrial composition adjustments affect energy consumption. Therefore, this paper introduces the changes in the share of the output of the secondary industry in GDP and the share of the tertiary industry from 2004 to 2013 as control variables. The data come from the China Regional Economic Statistical Yearbook.

Regional fixed effects: This article divides 285 prefecture-level and above cities into eastern cities, central cities, western cities, and northeast cities according to the China Regional Statistical Yearbook. $\mu_{j}$ represents the regional fixed effects; $\varepsilon_{j}$ is the error term.

Endogenous problems caused by possible reverse causality often occur in international trade research. In order to accurately estimate the impact of foreign trade on energy consumption, we must find suitable instrumental variables to eliminate the endogenous effects of variables. It must meet two conditions: one is that it can explain the reasons for the differences in the degree of openness of 
trade between cities, and the other is that it only affects energy consumption through foreign trade rather than other ways, that is, the requirements of relevance and exogeneity must be met at the same time. He Pei and Liu Ye [20] took the geographical distance between each city and its nearest port as an instrumental variable of FDI to studied its impact on China's environmental pollution and effectively solved the endogenous problem in the model. He pointed out that the geographical location of each city is fixed, and the distance from the nearest port will not be affected by any external factors, nor will it have any direct impact on environmental pollution and energy consumption. At the same time, the distance as an "iceberg cost" will have an important impact on the trade openness of various cities. Due to the high requirements of ports on natural conditions and the existence of economies of scale, the import and export of goods will be concentrated in a small number of large deep-water coastal ports. Therefore, this article selects the shortest geographical distance from each city to China's top ten ports as an instrumental variable of trade openness. The port standard is the top ten ports of foreign trade cargo throughput in the past five years, which are Dalian Port, Tangshan Port, Tianjin Port, Qingdao Port, Rizhao Port, Shanghai Port, Lianyungang Port, Ningbo-Zhoushan Port, Shenzhen Port, Guangzhou port ${ }^{2}$.

In addition, we select another instrumental variable: whether the city has a trading port in modern times. According to statistics, China was forced to open and actively open 114 trading ports during this time, which were distributed in 77 prefecture-level and above cities $^{3}$. As the commercial port is caused by historical reasons, it is neither affected by any other factors nor affects energy consumption. The commercial port has provided "first-mover advantage" and "historical inertia" for the development of foreign trade in cities. Therefore, it also meets the requirements of the instrumental variables in this article.

\subsection{Estimation Results}

\subsubsection{OLS Estimation Results}

Table 1 reports the OLS estimation results. The coefficient between changes in trade openness and energy consumption growth is positive and significant at the level $1 \%$, indicating that the development of foreign trade will promote the growth of energy consumption under the same conditions. Specifically, the change of trade openness is positively correlated with the scale effect and negatively correlated with the composition and technique effects, but the composition effect not significant. It shows that foreign trade has expanded the scale of economic activities and increased the energy consumption, but because foreign trade has expanded the market and strengthened the specialized division of labor, it provides conditions for the formation of scale economy, which can reduce ${ }^{2}$ The data comes from the website of the Ministry of Transport of the People's Republic of China. http://www.mot.gov.cn

${ }^{3}$ Zhu Zhen (2017) The Road to the Opening and Development of Chinese Ports. Economic Science Press, Beijing, 94-113. 
Table 1. The mechanism of foreign trade affecting energy consumption growth (OLS).

\begin{tabular}{|c|c|c|c|c|}
\hline \multicolumn{5}{|c|}{ OLS Estimation Results } \\
\hline & (1) & (2) & (3) & (4) \\
\hline & $\begin{array}{c}\Delta \text { Energy } \\
\text { consumption }\end{array}$ & $\begin{array}{l}\text { Scale } \\
\text { effect }\end{array}$ & $\begin{array}{c}\text { Composition } \\
\text { effect }\end{array}$ & $\begin{array}{c}\text { Technique } \\
\text { effect }\end{array}$ \\
\hline \multirow[t]{2}{*}{$\Delta$ trade } & $8.1790^{\star * *}$ & $10.1897^{\star * *}$ & 0.2849 & $-2.2956^{* * *}$ \\
\hline & $(2.3453)$ & $(2.7284)$ & $(0.3335)$ & $(0.7745)$ \\
\hline \multirow[t]{2}{*}{$\Delta \operatorname{LogGDP}$} & $11.7121^{\star *}$ & $16.2473^{\star * *}$ & 0.3718 & $-4.9071^{* * *}$ \\
\hline & $(4.6948)$ & $(5.4211)$ & $(0.6069)$ & $(1.3924)$ \\
\hline \multirow[t]{2}{*}{$\Delta$ second } & $-0.3737^{\star * \star}$ & $-0.4862^{\star * *}$ & $0.0484^{\star * *}$ & $0.0642^{* * *}$ \\
\hline & $(0.0725)$ & $(0.0826)$ & $(0.0115)$ & $(0.0212)$ \\
\hline \multirow[t]{2}{*}{$\Delta$ third } & -0.0660 & -0.1620 & $0.0199^{*}$ & $0.0760^{* * *}$ \\
\hline & $(0.0963)$ & $(0.1049)$ & $(0.0105)$ & $(0.0242)$ \\
\hline \multirow[t]{2}{*}{$\Delta$ price } & 0.0076 & $0.0151^{*}$ & $-0.0024^{* *}$ & $-0.0051^{*}$ \\
\hline & $(0.0079)$ & $(0.0088)$ & $(0.0012)$ & $(0.0029)$ \\
\hline \multirow[t]{2}{*}{ east } & 1.9981 & 2.1326 & -0.1980 & 0.0634 \\
\hline & $(1.9049)$ & $(2.0001)$ & $(0.2396)$ & $(0.3811)$ \\
\hline \multirow[t]{2}{*}{ central } & 0.3084 & 0.4392 & 0.0839 & -0.2147 \\
\hline & $(1.3407)$ & $(1.4100)$ & $(0.1856)$ & $(0.3555)$ \\
\hline \multirow[t]{2}{*}{ west } & 2.1036 & 2.0908 & $-0.5871^{\star * \star}$ & 0.6000 \\
\hline & $(1.3431)$ & $(1.4107)$ & $(0.2240)$ & $(0.3645)$ \\
\hline \multirow[t]{2}{*}{ Constant } & -2.8501 & $-5.3783^{\star}$ & -0.1706 & $2.6988^{\star * \star}$ \\
\hline & $(2.8963)$ & (3.2185) & $(0.3814)$ & $(0.9035)$ \\
\hline Observations & 285 & 285 & 285 & 285 \\
\hline
\end{tabular}

Note: Standard errors in parentheses: ${ }^{*} \mathrm{p}<0.1,{ }^{* *} \mathrm{p}<0.05,{ }^{* *} \mathrm{p}<0.01$; the values in parentheses are Robust Std. Err.

the energy consumption per unit output and improve the energy utilization efficiency. At the same time, with the deepening of specialized division of labor and the expansion of international commodity flows, the technique spillover effect of commodity flows will reduce the energy intensity, so that foreign trade can reduce energy consumption through the technique effect. In addition, it can be seen that the absolute value of the coefficient of foreign trade and scale effect is 10.19 , and the technique effect is only 2.30 , which indicates that foreign trade mainly affects energy consumption more through scale effect than technology effect, and the joint effect of the two promotes the energy consumption growth of foreign trade.

For other control variables, the change in GDP is a significant positive correlation with the increase of energy consumption, mainly through the positive scale effect and negative technique effect, but the composition effect is not significant, which are consistent with trade openness. Electricity price as an envi- 
ronmental regulation indicator has an impact on energy consumption through three channels, with the significant negative composition and technique effects. This shows that environmental regulation promotes the transfer of industries to clean industries and improves the energy utilization efficiency of various sectors, but the coefficient is relatively small, indicating that its restraint on energy consumption growth is limited. It may also be because the indicators selected in this paper cannot fully explain the strength of environmental regulation.

\subsubsection{Estimation Results}

This paper uses the 2SLS method to test whether the instrumental variables selected are valid, and the over-identification test and a weak instrumental variable test are also carried out. The results are shown in Table 2 and Table 3.

First, we performed an over-recognition test on the instrumental variables. As shown in the last row in Table 3, each $\mathrm{P}$ statistic value is greater than 0.1. Therefore, we accept the null hypothesis that the instrumental variables are exogenous and have nothing to do with the disturbance term and the first condition is satisfied. The second condition of effective instrumental variables is the correlation between instrumental variables and endogenous variables. As shown in the first-stage regression results shown in Table 2 , the instrumental variables (distance, port) have a better explanatory power for the endogenous variables (trade), and the $\mathrm{P}$ statistics value are all less than 0.05 , indicating that there is a strong correlation between two instrumental variables and trade openness. Then the weak instrumental variable test is performed. The results in Table 2 show that the F statistic is 12.722 , which satisfies the instrumental variable condition of more than 10 , and the p-value of the F-statistic is 0.0000 . At the same time,

Table 2. First-stage regression.

\begin{tabular}{|c|c|c|c|}
\hline \multicolumn{4}{|c|}{ First-Stage Regression } \\
\hline Variables & Coefficient estimate & $\mathrm{t}$ & $\mathrm{p}>|\mathrm{t}|$ \\
\hline distance & $-0.0002^{* * *}$ & -3.06 & 0.002 \\
\hline port & $0.188859^{* * *}$ & 3.40 & 0.001 \\
\hline$\Delta \log \mathrm{GDP}$ & $0.4438^{*}$ & 1.81 & 0.072 \\
\hline$\Delta$ second & $-0.0119^{* *}$ & -2.57 & 0.011 \\
\hline$\Delta$ third & -0.0021 & -0.51 & 0.608 \\
\hline$\Delta$ price & $-0.0016^{* *}$ & -2.34 & 0.020 \\
\hline \multicolumn{2}{|c|}{ regional fix effect } & \multicolumn{2}{|c|}{ Yes } \\
\hline \multicolumn{2}{|c|}{ Weak identification test (First stage F statistic) } & \multicolumn{2}{|c|}{12.722} \\
\hline \multicolumn{2}{|c|}{ Under identification test (P-value) } & \multicolumn{2}{|c|}{0.0000} \\
\hline \multicolumn{2}{|c|}{ Minimum eigenvalue statistic } & \multicolumn{2}{|c|}{13.8162} \\
\hline \multicolumn{2}{|c|}{ Observations } & \multicolumn{2}{|c|}{285} \\
\hline
\end{tabular}

Note: Standard errors in parentheses: ${ }^{*} \mathrm{p}<0.1,{ }^{* *} \mathrm{p}<0.05,{ }^{* * *} \mathrm{p}<0.01$. 
Table 3. The mechanism of foreign trade affecting energy consumption growth (using IV for trade openness).

\begin{tabular}{|c|c|c|c|c|}
\hline & (1) & (2) & (3) & (4) \\
\hline & $\begin{array}{c}\Delta \text { Energy } \\
\text { consumption }\end{array}$ & $\begin{array}{l}\text { Scale } \\
\text { effect }\end{array}$ & $\begin{array}{c}\text { Composition } \\
\text { effect }\end{array}$ & $\begin{array}{c}\text { Technique } \\
\text { effect }\end{array}$ \\
\hline \multirow[t]{2}{*}{$\Delta$ trade } & $25.5308^{\star * *}$ & $30.9491^{* * *}$ & -0.3671 & $-5.0513^{* * *}$ \\
\hline & $(6.3563)$ & $(7.5800)$ & $(0.6590)$ & $(1.6450)$ \\
\hline \multirow[t]{2}{*}{$\Delta \log$ GDP } & 2.0327 & 4.6672 & 0.7355 & $-3.3699^{* *}$ \\
\hline & $(6.5448)$ & $(7.3666)$ & $(0.6997)$ & $(1.5671)$ \\
\hline \multirow[t]{2}{*}{$\Delta$ second } & $-0.1842^{*}$ & $-0.2595^{\star *}$ & $0.0412^{\star * *}$ & 0.0341 \\
\hline & $(0.1111)$ & $(0.1232)$ & $(0.0101)$ & $(0.0259)$ \\
\hline \multirow[t]{2}{*}{$\Delta$ third } & -0.0405 & -0.1314 & $0.0190^{*}$ & $0.0720^{* * *}$ \\
\hline & $(0.1044)$ & $(0.1137)$ & $(0.0098)$ & $(0.0242)$ \\
\hline \multirow[t]{2}{*}{$\Delta$ price } & $0.0300^{* *}$ & $0.0419^{* * *}$ & $-0.0033^{\star *}$ & $-0.0087^{\star *}$ \\
\hline & $(0.0134)$ & $(0.0160)$ & $(0.0016)$ & $(0.0036)$ \\
\hline \multirow[t]{2}{*}{ east } & -3.6151 & $-4.5828^{\star}$ & 0.0129 & $0.9548^{\star}$ \\
\hline & $(2.5546)$ & $(2.6930)$ & $(0.2894)$ & $(0.5230)$ \\
\hline \multirow[t]{2}{*}{ central } & -0.2993 & -0.2879 & 0.1068 & -0.1182 \\
\hline & $(1.5388)$ & $(1.6610)$ & $(0.1863)$ & $(0.3616)$ \\
\hline \multirow[t]{2}{*}{ west } & $3.2046^{* *}$ & $3.4080^{* *}$ & $-0.6285^{* * *}$ & 0.4251 \\
\hline & $(1.4654)$ & $(1.5802)$ & $(0.2259)$ & $(0.3867)$ \\
\hline \multirow[t]{2}{*}{ constant } & -3.4619 & -6.1102 & -0.1476 & $2.7959^{* * *}$ \\
\hline & (3.3918) & $(3.7154)$ & $(0.3720)$ & $(0.8662)$ \\
\hline Observations & 285 & 285 & 285 & 285 \\
\hline Score chi2(1) & 1.23384 & 0.66735 & 1.28709 & 1.90293 \\
\hline $\mathrm{P}$ & 0.2667 & 0.4140 & 0.2566 & 0.1678 \\
\hline
\end{tabular}

Note: Standard errors in parentheses: ${ }^{*} \mathrm{p}<0.1,{ }^{* *} \mathrm{p}<0.05,{ }^{* * *} \mathrm{p}<0.01$; the values in parentheses are Robust Std. Err.

the minimum eigenvalue statistic is about 13.82 , which is larger than the corresponding critical value of 11.59 , which means that when the Wald test with a nominal size of $5 \%$ is applied to the significance of endogenous explanatory variables, if the true size is accepted less than $15 \%$, the null hypothesis of "weak instrumental variables" can be rejected. In short, we have reason to believe that there is no weak instrumental variable. According to the test results of 2SLS in Table 3, the sign and significance of trade openness coefficient are consistent with the results of OSL regression, which proves that they are not affected by endogenous, that is, trade openness is positively correlated with the scale effect, negatively correlated with the technique effect, and significantly positively correlated with energy consumption growth.

Based on the above analysis of the impact mechanism of China's foreign trade 
on the growth of energy consumption by using the IV method, it is concluded that during 2003-2014, foreign trade has a significant positive correlation with total energy consumption growth, a positive correlation with the scale effect, a negative correlation with the technique effect, and no significant composition effect. It reflects that foreign trade has an impact on the increase in energy consumption through the scale and technique effect, and the scale effect occupies a dominant position.

\section{Conclusions and Policy Implications}

This paper decomposes the energy consumption growth of 285 cities at prefecture-level and above in 2004-2013 into scale, composition and technique effect, and then discusses how China's foreign trade affects energy consumption through three decomposition effects. Therefore, the main conclusions of this paper are as follows:

First, whether China's 285 prefecture-level cities and above are classified according to the number of resident populations or the region, the results show that the scale effect is the main reason for the increase in energy consumption in each city, while the technique effect is the key factor to restrain the consumption. The composition effect also has a restraining effect, but its impact is minimal. The technique effect has a greater potential for energy conservation and consumption reduction in China. It is found that the size of the city population is an important factor affecting energy consumption, and cities with high population densities consume more energy. By comparing the energy consumption decomposition effects of the four major regional cities, it is concluded that the eastern region has the largest scale effect, the northeast and western cities have more obvious technique effects, and the composition effect has the largest contribution to the western cities.

In addition, based on the decomposition results, we use the IV method to find that foreign trade has a significant positive correlation with the energy consumption growth, a positive correlation with scale effect, a negative correlation with technology effect, and no significant composition effect during 2003-2014.

Combining the above conclusions, this paper proposes the following points: The expansion of China's overall economic scale in recent years is the fundamental reason for increasing energy consumption and exacerbating the contradiction between energy supply and demand. Therefore, we must break the traditional concept of "GDP is paramount", and avoid pursuing the huge pressure on energy supply brought by the high-growth economic development strategy. The technique effect provides a good intermediary for balancing the relationship between economic development and energy consumption. Therefore, while maintaining rapid economic development, it is necessary to implement environmental regulations for some high-energy-consumption cities and encourage enterprises to develop energy-saving technologies and products and conduct cleaner production. The composition effect has little effect on energy consump- 
tion as a whole, reflecting that the current industrial restructuring in China still needs to be adjusted and improved. We need to speed up the pace of industrial restructuring and reduce the proportion of high energy-consuming industries in the national economy to an appropriate level. At the same time, we should optimize the composition of foreign trade and speed up the specialization of the industry through foreign trade. China's national conditions are complex, and there are obvious differences between cities in terms of energy consumption, industrial composition, and technological level. Therefore, governments should take measures according to local conditions to carry out energy conservation and consumption reduction.

\section{Conflicts of Interest}

The author declares no conflicts of interest regarding the publication of this paper.

\section{References}

[1] Nasreen, S. and Anwar, S. (2014) Causal Relationship between Trade Openness, Economic Growth and Energy Consumption: A Panel Data Analysis of Asian Countries. Energy Policy, 69, 82-91. https://doi.org/10.1016/j.enpol.2014.02.009

[2] Kyophilavong, P., Shahbaz, M., Anwar, S. and Masood, S. (2015) The Energy-Growth Nexus in Thailand: Does Trade Openness Boost up Energy Consumption? Renewable and Sustainable Energy Reviews, 46, 265-274.

https://doi.org/10.1016/j.rser.2015.02.004

[3] Nnaji, C.E., Chukwu, J.O. and Nnaji, M. (2013) Does Domestic Energy Consumption Contribute to Exports? Empirical Evidence from Nigeria. International Journal of Energy Economics and Policy, 3, 297-306.

[4] Erkan, C., Mucuk, M. and Uysal, D. (2010) The Impact of Energy Consumption on Exports: The Turkish Case. Asian Journal of Business Management, 2, 17-23. https://doi.org/10.4018/jabim.2010070103

[5] Katircioglu, S.T. (2013) Interactions between Energy and Imports in Singapore: Empirical Evidence from Conditional Error Correction Models. Energy Policy, 63, 514-520. https://doi.org/10.1016/j.enpol.2013.08.037

[6] Sadorsky, P. (2011) Trade and Energy Consumption in the Middle East. Energy Economics, 33, 739-749. https://doi.org/10.1016/j.eneco.2010.12.012

[7] Ghani, G.M. (2012) Does Trade Liberalization Effect Energy Consumption? Energy Policy, 43, 285-290. https://doi.org/10.1016/j.enpol.2012.01.005

[8] Shahbaz, M., Nasreen, S., Ling, C.H. and Sbia, R. (2014) Causality between Trade Openness and Energy Consumption: What Causes What in High, Middle and Low Income Countries. Energy Policy, 70, 126-143. https://doi.org/10.1016/j.enpol.2014.03.029

[9] Sbia, R., Shahbaz, M. and Hamdi, H. (2014) A Contribution of Foreign Direct Investment, Clean Energy, Trade Openness, Carbon Emissions and Economic Growth to Energy Demand in UAE. Economic Modelling, 36, 191-197. https://doi.org/10.1016/j.econmod.2013.09.047

[10] Shahbaz, M., Khan, S. and Tahir, M.I. (2013) The Dynamic Links between Energy Consumption, Economic Growth, Financial Development and Trade in China: 
Fresh Evidence from Multivariate Framework Analysis. Energy Economics, 40, 8-21. https://doi.org/10.1016/j.eneco.2013.06.006

[11] Goldemberg, J. (1984) Energy Problems in Latin America. Science, 223, 1357-1362. https://doi.org/10.1126/science.223.4643.1357

[12] Sadorsky, P. (2012) Energy Consumption, Output and Trade in South America. Energy Economics, 34, 476-488. https://doi.org/10.1016/j.eneco.2011.12.008

[13] Arouri, M., Shahbaz, M., Onchang, R., Islam, F. and Teulon, F. (2013) Environmental Kuznets Curve in Thailand: Cointegration and Causality Analysis. The Journal of Energy and Development, 39, 149-170.

[14] Grossman, G.M. and Krueger, A.B. (1991) Environmental Impacts of a North American Free Trade Agreement (No. w3914). National Bureau of Economic Research, Cambridge. https://doi.org/10.3386/w3914

[15] Cole, M.A. and Elliott, R.J. (2003) Do Environmental Regulations Influence Trade Patterns? Testing Old and New Trade Theories. World Economy, 26, 1163-1186. https://doi.org/10.1111/1467-9701.00567

[16] Tsurumi, T. and Managi, S. (2010) Decomposition of the Environmental Kuznets Curve: Scale, Technique, and Composition Effects. Environmental Economics and Policy Studies, 11, 19-36. https://doi.org/10.1007/s10018-009-0159-4

[17] Grether, J.M., Mathys, N.A. and de Melo, J. (2009) Scale, Technique and Composition Effects in Manufacturing $\mathrm{SO}_{2}$ Emissions. Environmental and Resource Economics, 43, 257-274. https://doi.org/10.1007/s10640-008-9237-5

[18] Yuan, X. (2010) Trade Growth and China's Environment: Scale, Technique and Composition Effects. World Economy Study, 10, 57-62+89.

[19] Shapiro, J.S. and Walker, R. (2015) Why Is Pollution from US Manufacturing Declining? The Roles of Trade, Regulation, Productivity, and Preferences. US Census Bureau Center for Economic Studies Paper No. CES-WP-15-03. https://doi.org/10.2139/ssrn.2555604

[20] Pei, H.E. and Ye, L. (2016) The Effect of FDI on China's Environmental Pollution: A Research Based on Instrument of Geographical Distance. Journal of Central University of Finance \& Economics, No. 6, 9. 